\section{THE RECENT DEVELOPMENTS OF COSMICAL} PHYSICS*

THERE are two conflicting theories with regard to education. The extreme partisans of one of these would have us believe that the great object of education is not so much to inform as to discipline the mind-the subject taught in a seminary may not in itself increase the student's real knowledge, yet if it tend to discipline his mind, it has proved its value in their eyes as a branch of education.

According to the upholders of this theory, our object in going to school is to leave it with a mind enlarged in its capacity for acquiring knowledge rather than stored with knowledge itselfhaving trained the soldier well they would send him without scruple into the enemy's country, not only to fight his own way but to find his own weapons.

But there is another and opposite class of theorists who regard education not as an agent for training the mind so much as a means of storing it with knowledge. The extreme partisans of this theory would teach the student nothing but what is of apparent and immediate use; above all things they would teach him the sciences, both in their principles and also in the various details of their applications to the industrial arts of life.

The mind of the student who has undergone a training of this kind carried to its extreme, resembles the inmate of a house which is not so much well-furnished as filled full of furniture. In the accumulation of mere material, anything like plan or principle has been forgotten. It ought to be remembered that the value of a fact lies not in its existence somewhere in the mental stnrehouse, but in the readiness with which the mind can find it when required.

Now between these two extreme theories it is surely possible to steer a middle course-it is possible to avoid grounding on Scylla without being swallowed up in the vortex of Charybdis. In the material world, what would be said to a man who insisted upon developing bodily strength by a course of gymnastics without reference to food, or of another who insisted upon doing the same by a course of diet without reference to exercise? But is the separation more natural in the mental world? Is not that mind most perfectly disciplined which is at the same time most perfectly informed? The student who has been disciplined by only one branch of knowledge is, I venture to think, the possessor of a mind only partially disciplined, as it is only partially informed. He may not easily perceive his deficient discipline, but in after life he must often have cause to regret his deficient information. Nor is he whose mind is inordinately stored withiscentific details one whit better off. Facts in education ought to be strictly subordinated to principles. A sound principle of science clearly understood will embrace a great multitude of facts, just as a simple rule of arithmetic will enable us to obtain a thousand products, each of which we should have to remember were it not for the rule. And in other branches of science, if the triumph of principle be not so apparent, it is only because we have a less accurate knowledge of its funclamental laws. It would be difficult indeed to say how many of the failures in the various walks of life are due to the neglest or ignorance of some principle which has been either omitted or dismissed from our calculations. From our leaders downwards we are a nation systematically ignoring principles, and in the minds of many a high esteem for fact is lield to be quite consistent with a contempt for theory. A theory is not regarded as the very sap and life-blood of the tree of knowledge, but rather as the mildew that blights its leaves, or the worm that gnaws its root. Facts and theories are esteemed by this class of men to be sworn foes to each other, and the philosopher is supposed to live in a world of his own, rather hostile than otherwise to the world around him.

The existence of the two extreme educational theories to which I have alluded would thus seem to indicate the wisdom of a middle course. We ought to start from a platform as comprehensive as possible. Literature and science ought to go hand in hand in producing the well-trained and well-informed disciple. And while there ought to be a broad basis of instruction common to all, there should be raised upon this common basis severa! distinct departments, so that the student may have the opportunity of attaining proficiency in that of his choice.

Prof sssor Stewart next touched upon the subject of energy.

* Extracted from a Lecture delivered at Owens College, Manchester, introductory to the Session $x \varepsilon_{70-71}$, by Professor Balfour Ste xari, LL.D., F.R.S.
If an egry be allowed to rest on its shorter axis, it will remain stationary, and any attempt to alter its posicion will be resisted by the egg. But the case will be different if we succeed, as perhaps we may, in causing it to stand on its longer axis, for in this position the slightest force will cause it to topple over. In the first case the egg is in stable, but in the second case it is in unstable, equilibrium.

If it stand upon its longer axis at the very edge of a table, we cannot tell whether the first slight breath of air will cause it to fall inwards upon the table or outwards over the table, to be dashed to pieces on the floor. It is a case where a very slight cause may determine a very considerable issue as far as energy is concerned. Whether the egg will retain its energy of position by falling on the table, or whether it will convert this into the energy of motion, and ultimately into heat, by falling upon the floor, is an issue that depends upon a cause too minute to come within the scope of our calculations.

Now we have two types of machines, and in one of these we take advantage of the principle of stability, while in the other. we use the principle of instability. A clock is a very good instance of a machine of the first kind. When a gnod clock has been wound up, we are perfectly sure that at noon to. morrow both its hands will stand at twelve, and that its weight will have fallen through a distance which we can calculate with the utmost exactness, if we take the troubla, all its movements being capable of the most rigorous calculation. On the other. hand, a mine that is about to be fired by means of an electric battery is a machine or combination in which advantage is taken of :nature's unstable arrangements. The powder which is about to explode represents chemical instability, just as the erg on its longer axis represents mechanical instability. The slightest percussion, the smallest spark will rouse the imprisoned giant which it contains into volcanic energy. This spark has to be sent from a distance by the galvanic battery, and to do this we must complete the circuit. We cause the two wires to approach each other until they are only a very small fraction of an inch apart, but the contact is not yet complete-another touch, so slight as to be imperceptible, and the current passes, the powder is ignited, the mine explodes, and the fortress is hurled into the air. In such machines, great results, great transmission of energy, are due to the most trivial disposing causes. It depends at last upon the smallest conceivable movement of the wires conveyin the current whether or not the fortress is to perish.

Nature also employs these two varieties of mechanism. In the solar system we have a clock on a large scale, only very much more accurate than any time-piece we can produce. The move ments of every planet in the solar system are susceptible of the most rigorous calculation, and we have only to point our tele. scope properly in order to tell to the fraction of a second when a given planet will cross the field of view.

But in the living forms with which this world is so plentifully endowed, we have machines, which, viewed in their relation to matter, belong to the second order we have described. The object here is not regularity, but rather freedom of action. The motion of an animal is not like that of a planet - the latter yields to calculation, but the former defies it. Now it is probably somewhere in the mysterious brain chamber that the delicale directive touch is given which determines our movements, just as the slightest possible touch to the wire in the battery chainber explodes the distant mine. That mysterious thing we call life is not a bully who swaggers out into the open universe, upsetting the laws of energy in all directions, but rather a consunimate strategist, who, sitting in his chamber before his wires, directs the movements of a great army.

While we are thus led to confine the directive action of life to the very boundary of the universe of energy, it must not, however, be supposed that we have solved the problem as to the nature of life. We have only driven the difficulty into a border land of thick darkness, into which the light of knowledge has not yet been able to penetrate. If there be truth in these statements, and if we see in a living being a machine in which great results are produced by an exceedingly small primeval impulse, are we not led to expect that the unstable forms of nature will here be largely made use of? We must not therefore be surprised that the materials of our bodily frames are eminently liable to decay, or that the very intensity of our life is to be measured by the rate of change taking place in the tissues of our bodies, so that possibly those parts which have during life the noblest and mosi delicate offices to perform are the very first to perish when lite :s extinct.

But this unstable matter, which is so wonderfully worked int 
our frames, is derived from the food we eat. This food does two things for us: it gives us energy in the first place, and in the second it furnishes our frames with a quantity of delicately organised tissue. But food is ultimately derived from the vegetable kingdom, and that kingdom derives it from the sun, so that we are led to regard our luminary as the ultimate material source not only of our energy, but also of our delicacy of construction.

To come now to our own luminary-very remarkable strides have lately been made in our knowledge of its physical constitution. It is difficult to say when and by whom the existence of sun spots was first remarket. Galileo, however, was the first to use them as the means of determining the elements of the sun's rotation. 'Mesides these black spots on the sun's surface, equally mysterious forms have been seen to surround the sun on the various occasions of a total eclipse--these generally went by the name of red flames or red protuberances. Mr. Warren De La line was the first to prove that these phenomena were at tacherl to the sun himself, and that the only office of the moon during an eclipse was to subdue the general light sufficiently to render them visible to the eye. While the red flames thus became objects of cosmical interest, Schwabe in Germany and Carrington in this country had both clone much to increase our knowledge of sun spots. Schwabe, by a patient course of forty years' (b)servations, had proved the existence of a well-marked periodical fluctuation in the amount and frequency of sun spots, the period of which was about eleven years. Carrington, again, had shown that the region of spots was a somewhat limited one, extending to about $20^{\circ}$ or $30^{\circ}$ on either side of the solar equator, so that a spot never appears at the sun's pole, and he had also detectcd a proper motion of spots. Schwabe and Carrington hart, however, confined themselves to mapping down accurately what they saw ; but De La Rue, by the introduction of celestial whotorraphy, was enabled to obtain sutorraphs of the sun which might be studied at leisure with an absolute certainty of their beingr correet. A large number of such pictures has been already olutained, and they are in the process of examination by Mr. De La Rue, and thuse associated with him in this research.

Some of the preliminary results of this examination have alreacly been pullishert, and they seem to point to a connection hetween the behaviour and frequency of sun spots and the positions of the chief planets of the svstem.

Our acquaintance with the red flames has extended as rapidly as our knowiedge of sun s:ots. Tt was discovered independently by lanssen and Lockyer, that these strange protuberances yield to the spectroscope under ordinary conditions of the sun, and without the necessity of waiting for a total eclipse. They exist, in fact, always round the sun, but their brightness is quenched in the diffused light which surrounds the sun's border. When, fowever, we apuly a sufficiently powerful spectroscope, the diffitied light--consisting of ordinary sun light, and therefore contuining a great variety of rays - is drawn out into a long spectral ribhom, and has its brightness scattered or diffused over the various parts of this ribbon, while on the other hand the light from the red flames, consisting only of one or two kinds, appears in the spectrosenpe as nne or two bright lines not having their intemsity weakened by the scattering action of the spectroscope. Thisy, therefore, stand out in the field of viesw, while the ordinzry light disappears. L.ockyer has found, by this means, that there is an envelope of incandescent hydrogen surrounding the slowing surface of the sun. into which there are frequent injections of heated matter from beneath, and in which there are violent huricanes o!ten moving at the rate of 100 miles a second. By the laboratory labours of Frankland and Lockyer, taken in connection with the solar observations of the latter, there is, I think, a probability of our ultimately ascertaining the pressure and the temperature as well as the chemical composition of the atmosphere of our luminary.

Descending now from the celestial bodies to our own earth, there is some reason to suppose that we are knit to our luminary, and possibly through him to the other members of our system by snme other bond, besides that usually recognised. General Sir E. Sabine appears to ha:e proved that disturbances of the carih's magnetism take place most frequently in those years in which there are most sun spots. This is confirmed by the experience of the present year, during which we bave had a great $n:$ :mber of sun spots, and frequent and large disturbances of the earth's magnetism

I have a' ready alluded to a possible connection between the hehavi ur of sun spots, and the positions of the planets; to which w may add, that Schwab: and nther observers imngine that thry have discovered traces of a periodical variation in the appearance of the planet Jupiter. All therubservations would appear to indicate the existence of some un':in' wn bond between the different members of the solar system.

But that department of cosmical physics which is of most immediate interest to ourselves, is undoubtedly the meteorology of our globe; and here it is of great importance; to know whether the earth's climate and atmosphere are influenced in any way by the changes taking place in the atmosphere of the sun. Such a connection has not yet been traced, but it has hardly yet been sought for in a proper manner. Recent observations discussed by Baxendell, lead us to think there may be some connection between the daily changes in the earth's magnetism and the daily motions of the air. Coupling this with the fact that the frequency of terrestrial magnetic disturbances would appear to be connected with that of sun spots, we are led to contemplate at least the possibility of some connection between meteorology and sun spots.

If these remarks are of any value, they tend to indicate the probable union of the various branches of observational inquiry into one great cosmical research, and point to the wistom of very close union between the workers in the cognate fields of meteorology, terrestrial magnetism, and celestial physics.

At the present moment the prospects of meteorology are more hopeless than those of the other two branches. Our knowledge of the motions of the various components of the earth's atmosphere is extremely limited, and yet without this knowledge it is impossible to connect meteorology with the other branches of cosmical inquiry. If we endeavour to analyse the causes of this backward state of meteorological research, the first and most apparent is the maguitude of the problem.

We are too intimately associated with the earth and its atmo. sphere to be easily able to tell its motions. Strange to say, the meteorology of the sun is more easily studied than that of the earth, and we know already as much about the strength of solar storms as we do about that of terrestrial hurricanes.

But another cause of the backward state of Physical Meteoro. logy arises from the fact that there are two branches of science, each of which may be furthered by meteorological observations. There is first the physiological branch of meteorology, the object of which is to trace the influence of climate upon animal and vegetable life; and there is next the physical branch, the object of which is to study the physics of the earth's surface, and more especially the motions of its atmosphere.

It is now high time that a separation should be made in the mind of the observer between these two branches of research. If he would rather pursue the physiological inquiry, let him say so definitely, but if he wish to pursue physical meteorology, let him clearly keep before his mind the object of all his labours. He should ask himself the question, what is the best system of observation, and what is the best method of reduction, to advance the great object of physical meteorology a knowledge of the motions of the earth's atmosphere, and of the causes thereof? He should not fix upon a system of observa. tions and a method of reduction that may possibly, but upon one that must necessarily, further this great object.

I have thus endeavoured in a few words to bring before you the recent advances in cosmical physics. Besides this, there are two other no less important branches of physical inquiry. We have the physics of organised beings, and we have also molecular physics. But there is this difference between these two branches and that of which I have now spoken:- To forward physiology or molecular physics we chiefly require experiment, but to forward cosmical physics we chiefly require observation. You are all aware that at the present moment a Royal Commission is inquiring as to the relation between Science and the State; and perhaps, therefore, you will permit me the opportunity of stating my views as to the manner in which this very necessary assistance may best be given. I think that those branches of science which demand for their extension experiments not requiring very great time may be furthered with much advantage in institutions such as Owens College. I believe it to be advantageous to bring the highest class of playsical teaching into contact with research. If Government be disposed to grant pecuniary aid to such researches, an extension of the allowance made annually to the Government Grant Committee of the Royal Society would appear to be a very legitimate way of accomplishing this object.

The scientific professors of a college would thus have to state the aim of their research to a committee of the Royal Society entrusted with the disposal of Covernment means, and the requi site funds would be forthcoming. No one, I think, can doubt 
that the small sum of $\mathrm{x}, 000 t$. annually entrusted by Government to the Royal Society for miscellaneous experiments, is administered in a most praiseworthy manner ; and if Government would be ready to grant, and the Royal Society willing to undertake, an extension of this trust, it would, I think, be a great point gained for this class of physical experinents. (I speak only of experiments, but the encouragement of experimenters is a point of equal importance.) But when we come to experiments and observations requiring great time, the case is very different. Certain experiments, whether from the great time they require or the great expense they demand, cannot be well performed in a college; while routine and long-continued observations such as those connected with the various branches of cosmical physics are of such a nature as to require a central establishment to superintend their organisation and reluction. There is thus, I think, the necessity for a central establishment of some kind devoted to that class of experiments and observations requiring great time, great space, and great expense for their completion.

Referring more particularly to Cosmical Physics, I feel convinced that meteorology should be pursued in connection with terrestrial magnetism and solar observations; and were a wellconsidered scheme for solving this great problem fairly introduced, I am sure that scientific institutions and individuals throughout the country would do all that they possibly could to promote this most important branch of physical research.

\section{THE BRITISH ASSOCIATION}

\section{SECTIONAL PROCEEDINGS}

\section{ISection A.-Matrmematical and Physical Science}

Barometric Predictions of Weather.-Mr. F. Galton, F.R.S. It has long been an established custom to consult the barometer to learn what the weather is likely to be. Now, I propose to investigate the value of this form of barometric authority by showing that it is possible to make strict use of the rules of prediction, notwithstanding the vagueness with which they are enunciated, and then, by comparing a series of carefully-made predictions with facts, tn measure the degree to which they correspond. There is another form of barometric authority about which I do not propose to say anything here, namely, where the barometer is consulted in connection with the daily Weather Report. Owing to the new data thereby introduced, an inquiry into the value of those predictions would have to be conducted along an altogether different line to that which $I$ am about to follow.

My comparisons between predictions and facts will be based upon the tracings of the continuously self-recording instruments at Falmouth, established by the Meteorological Committee appointed by the Royal Society, which have been published for the first quarter of the year 1869 . It is, however, right to add, that some years ago I made an elaborate inquiry into the Dublin observations during a much longer time, which led, so far as it went, to the same conclusions as now.

I did not publish those inquiries, because I had a misgiving which was never wholly removed until I had the opportunity now afforded by the above-mentioned publication of studying the continuous records of instruments in large numbers. It is said that instrumental changes commonly occur in sweeps so large and steady that future changes in them may be to some extent predicted by a knowledge of what has occurred. An analysis of the Dublin observations, made at intervals of three hours, contradicted this assertion, but I felt they might be held insufficient to dispose of it. It might fairly be said that three hours was too long an interval between the observations, and that if the instruments had been read off more frequently, I should have been led to different conclusions. It was necessary to settle this doubt, because, as there is certainly some correspondence between the barometer and the weather, it followed that if it be possible to predict the movements of the former, we shall also, as a matter of course, be able in some degree to predict the latter. I therefore examined the tracings which represent the continuous records of the barometer and other instruments with great interest and care, and soon convinced myself that the irregularities of the barogram and thermogram were far too great to enable us to predict their course from moment to moment. We have only to place a paper upon them, so as to hide what follows any given instant, and to expose what precedes it, and to move the paper forward, step by step, guessing beforehand what we are to see, to be convinced of the vanity of our expectations. This basis of weather prediction is so manifestly unsound, that I shall not take any further notice of it.

We all know that the weather with which the barometer sympathises, is considered to consist of three independent variables - the velocity of the wind, its temperature, and its dampness. It is a question how far the direction of the wind need be reckoned as a fourth distinct influence. We also know that the velocity of the wind is the most important; it is said that when the two other variables are unchanged, and the velocity of the wind alone varies, the barometer may range through two inches, but that it can only range through a quarter as much when either the temperature or the damp are the sole variables. I therefore feel at liberty to begin by simply comparing the changes of the wind's velocity with those of the barometer, in order to obtain a provisional idea of the manner in which they go together.

Two things are very clear at first sight- the one is that the wind's velocity passes through numberless tumultuous variations of which the barometer takes no cognizance, and the other is that a connection decidedly exists between periods of storm and of fine weather, with barometric falls and rises. What, then, do we mean by periods of storm? How long is the period during which the velocity of the wind should be summed up and averaged, in order to be made to accord most closely with the barometer?

I made several trials, and protracted the results on the same time-scale as the corresponding barograms. The ordinates of the different points whose position I calculated represented the average velocity of the wind during a.definite period at the moment indicated by the point ; then I connectel the points by a line drawn with a free hand. In this way I constructed a curve, every point of which rcpresented the average velocity of the wind during the space of one hour, being half an hour before and half an hour after the instant corresponding to that point. In another curve, a three-hour period was adopted, and so on. Below all these I copied the barogram.

There could be no doubt, on inspecting those lines, that a onehour period is far too short, that a three-hour is better, a six-liour better still, and that a twelve-hour is as good as can be obtained. Any period between twelve and sixteen hours seemed equally suitable for adoption, some parts of the curve improving in correspondence as the period was lengthened, and others falling off; but, after a sixteen-hour period, the curve of wind velocity became less varied than the barugram, and the maximum of correspondence was passed. Finding the twelve-hour system the most convenient to eniploy, I have adupted it here, leaving it to be understood that a different period might be taken within the limits named, without sensibly affecting the results.

The correspondence between the wind curves thus obtained and the barograms is respectably close, there being hardly a dip or rise in the one which has not a counterpart in the other; but they are far from being exactly alike. Neither do the changes, of course, in the two curves, bear an invariable retation in point of time to one another; but, as neither of them la:rs habitually behind, they must be considered on the average simultaneous.

I do not find the correspondence sensibly affected by making broad allowances for the neglected variables. Thus, on marking the epochs of cold and dry polar winds in one way and those of warm and moist equatorial winds in another way, little or no new light was thrown on the reason of the want of coincidence of the two curves. It seemed to me, from this trial, that the influence of temperature, damp, and wind's direction, is considerably less than was commonly believed.

The parallelism of tie curves was as close in extreme positions as in mean ones, which confirms the common statement that we must look to differences of barometric hei; ht and not to the absolute height for signs of changing weather.

All this is easily compressed into a formula $: h_{1} h_{2}$ are two successive barometric heights a few hours apart ; $v_{1}$ (I2) $v_{2}$ (12) are the corresponding twelve-hour averages of wind velocity; $m$ is a simple factor to be determined by trial, then

$$
h_{1}-h_{2}=m\left\{v_{1}(12)-v_{2}(12)\right\}
$$

+ a function of temperature and another of damp, neither os which is of much importance.

$m$ is strictly constant only for the same season, because the range of the barometer is wider in winter than in summer, for the same latitude hecatse its range is smallest at the equator,and for the same locality bec: use the wind's velocity may be checked by geographical conditions. Bearing this in mind, the value of $i n$ for the first quarter of the year, at Falmonth, as, 